\title{
Controle de infecção oral em pacientes internados: uma abordagem direcionada aos médicos intensivistas e cardiologistas
}

\author{
Oral infection control in hospitalized patients: \\ an approach to cardiologist and intensive care units doctors
}

\author{
Sérgio Kahn ${ }^{1}$ \\ Elen de Saboya M angialardo ${ }^{1}$ \\ Carlos Henrique Garcia ${ }^{1}$ \\ Fátima $\mathrm{M}$ aria Namen ${ }^{1}$ \\ João Galan Júnior ${ }^{1}$ \\ Walter Augusto Soares M achado ${ }^{1}$
}

${ }^{1}$ Universidade Veiga de Almeida. Rua Ibituruna 108, Tijuca. 20271-020 Rio de Janeiro RJ.

skahn@openlink.com.br
Abstract This paper aims to find the current level of periodontal med-care knowledge, as well as the possible existence of some oral infection control protocol regarding hospitalized patients. Our sample gathered 110 cardiologists and intensive care units doctors selected from medical teams of five Rio de Janei ro hospitals. Preliminary numbers: $75.4 \%$ said to have heard something about Periodontal M edicine, although only $30 \%$ out of this group admitted to have read something concerning such subject. On the other side, only $2.7 \%$ of the sample informed to do consistent information searching along their patients anamnese, while $58.2 \%$ out of this group admitted such procedure conditional to the patient's general state at the due moment. Through such numbers, we tend to comeup to the conclusion that, beit either through direct or indirect Periodontal M edicine technical information (and consequently with regards to the absolut importance of preservation and control of oral biofilm and its impact on one's systemic health), the matter has been dimly spread among medical groups. Thesearch also revealed the probability that Rio de Janeiro hospitals lack either units or agents designed for prevention and control of oral infection; consequently, such organizations do not have any kind of protocols, reliable or not, concerned to oral infections.

Key words Infection control protocol, Periodontal disease, Systemic diseases, Cardiovascular disease
Resumo 0 objetivo do presente estudo foi verificar o grau de conhecimento médico sobre medicina periodontal e verificar a existência de algum protocolo de controle de infecção da cavidade oral em pacientes internados em hospitais. Para tal, 110 médi cos cardiologi stas e intensivistas lotados em cinco hospitais no município do Rio de Janeiro foram entrevistados. Dentre os indivíduos, $75,4 \%$ afirmaram ter conhecimento sobre 0 termo medi cina periodontal; entretanto, apenas $30 \%$ declararam já ter lido al go a respeito. A penas 2,7\% dos médi cos possuem o hábi to de coletar informações sobre a história odontológica de seus pacientes e 58,2\% afirmaram que essa conduta é condicional ao quadro apresentado pelo paciente. Com base nos dados obtidos, pode-se concluir que 0 conhecimento sobre medicina periodontal e, consequentemente, sobre a importância do controle do biofilme oral na manutenção da saúde sistê mica, apresenta-se pouco difundido entrea classe médica. Verificou-se não haver setor ou pessoa responsável pelo controle de infecção oral dentro doshospitaisavaliadose, consequentemente, a não existência de qualquer protocolo, eficaz ou não, de controle de infecção oral nessas unidades. Palavras-chave Controle deinfecção oral, D oença periodontal, D oença si stêmica, D oença cardiovascular 
Introdução

A distinção entre a medicina e a odontologia re monta a meados do século XIX, época da fundação da primeira faculdade de odontologia do mundo, em Baltimore. Centenários anos de afastamento causaram uma perda enorme na ênfase do impacto da doença sistêmica sobre a cavidade bucal e, mais importante, do impacto da doença bucal sobre a condição sistêmica do organismo. Entretanto, o grande avanço da odontologia e da medicina em busca de um melhor entendimento da fisiopatologia humana possibilitou um comportamento científico mais holístico ehumanizado, no qual as especialidades novamente confluem em direção a um objetivo comum: o de restabelecer e manter a saúde do indivíduo.

A odontologia tem evoluído e direcionado seus estudos na busca de uma maior compreensão da doença periodontal a fim de dimensionar a influência e interação das bactérias orais nos desequilíbrios e agravos da saúde sistêmica. Há mais de uma década, estudos interessados na presença e influência de bactérias da flora bucal nos diversos meios teciduais vêm demonstrando forte associação entre esses patógenos e quadros infecciosos à distância. Alguns autores relatam que as doenças orais podem desempenhar um papel importante na etiopatogenia de diversas enfermidades sistêmicas, tais como doenças cardíacas coronárias, acidentes vasculares cer ebrais, endocardite bacteriana, diabetes mellitus einfecção respiratória. Dentre as doenças orais, destaca-sea doença periodontal, em quea presença de microorganismos gram-negativos, semelhantes aos das várias infecções crônicas e respiratórias, ocorre em muitos casos ${ }^{1-3}$.

Outros como Offenbacher et al. ${ }^{4}$ demonstraram que as infecções por patógenos periodontais representam um fator de risco significativo para nascimento prematuro e baixo peso (PLBW), estimando que $18,2 \%$ dos PLBW sejam atribuídos a gestantes com doenças periodontais.

I números trabalhos científicos têm demonstrado a grande relação entre o biofilme presente nas doenças orais e o curso das infecções respiratórias, principalmente da pneumonia por aspiração, sendo esta o tipo mais comum de pneumonia nosocomial e, como tal, uma séria causa de morbidade e mortalidade dentre os pacientes internados ${ }^{5,6}$.

Alguns clínicos têm observado que as doenças cardiovasculares e periodontais, ambas crô- nicas e multifatoriais, têm em comum uma base genética de susceptibilidade e também componentes importantes, como os hábitos relacionados à dieta, à higiene e à prática do tabagismo, dentre outras. Componentes esses relevantes na etiopatogenia da cárie e da doença periodontal, tanto quanto das doenças cardiovasculares. Portanto, segundo Beck et al. ${ }^{7}$, ambas as doenças apresentam uma série de características em comum; ocorrem com maior frequência em pessoas mais velhas, do sexo masculino, com baixo nível socioeconômico e cultural, fumantes, diabéticos com quadros de estresse e com marcante predisposição genética.

0 assunto abordado no presente trabalho trata da importância delegada ao controle de infecção oral em pacientes internados em hospitais. Evidências nos trabalhos de Yoneyama et al. ${ }^{8}$; Adachi et al. ${ }^{9}$ eFourrier et al. ${ }^{10}$ têm demonstrado que o controle de infecção oral em pacientes internados diminui o número de casos de infecções nosocomiais como, por exemplo, casos depneumonia por aspiração ecomplicações cardíacas. De Riso et al. ${ }^{11}$ testaram a descontaminação orofaríngea utilizando digluconato de clorexidina a $0,12 \%$, em pacientes que seriam submetidos a procedimentos cirúrgicos, obtendo um resultado bastante satisfatório com redução do índice de infecção nosocomial em $65 \%$.

Baseando-se na literatura que nos fundamenta para uma atuação preventiva às infecções nosocomiais e agravos à saúde através do controlequímico emecânico da microbiota oral dos pacientes internados e incapacitados de realizálo autonomamente, buscou-se avaliar o conhecimento científico de médicosintensivistas ecardiologistas sobre a importância destes procedimentos, como também verificar a existência de protocolos para tal finalidade em cinco hospitais situados na cidade do Rio de Janeiro.

\section{Objetivos}

A presente pesquisa teve como objetivo avaliar quantitativamente e qualitativamente $o$ conhecimento e a prática do controle de infecção oral realizado em pacientes internados em hospitais situados na cidade do Rio de Janeiro através de uma abordagem direcionada a médicos atuantes nos centros de terapia intensiva e unidades coronarianas. 


\section{Métodos}

Foram avaliados 110 médicos cardiologistas e intensivistas lotados em cinco hospitais (dois municipais, um estadual, um federal eum particular) situados na cidade do Rio de Janeiro que possuíssem centros de terapia intensiva e unidades coronarianas em plena atividade. Entre os 110 indivíduos, havia $52(47,2 \%)$ cardiologistas, $26(23,6 \%)$ intensivistas e $32(29,1 \%)$ entrevistados possuíam as duas especialidades, terapia intensiva e cardiologia. Os profissionais médicos cardiologistas e intensivistas lotados nos hospitais selecionados para este estudo foram avaliados desde que concordassem livremente em colaborar com o mesmo, após leitura e assinatura determo de consentimento livre esclarecido.

Para a coleta de dados, foi elaborado um questionário contendo 24 questões mistas, o qual foi devidamente respondido em entrevistas aos sujeitos da pesquisa. Os dados coletados foram analisados e interpretados segundo as normas técnicas ditadas pela Fundação Instituto Brasileiro de Geografia e Estatística (IBGE) e apresentados em tabelas e gráficos. Foi utilizado o teste do qui-quadrado $\left(\chi^{2}\right)$ para verificação da significância estatística quando $p<0,05$.

A presentepesquisa foi submetida ao Comitê de Ética e Pesquisa (CEP) da Universidade Veiga de Almeida assim como aos respectivos CEP de cada unidade hospitalar participante do estudo.

\section{Resultados}

Diante de uma abordagem geral, como ilustrado no Gráfico 1, entre os 110 médicos entrevistados, $63(57,3 \%)$ acreditam haver relação entre doenças orais e doen ça coronarianas; 96 (87,3\%) afirmam ser possível uma relação causal entre pneumonia e doenças orais; 48 (43,6\%) verificam uma associação positiva entre as últimas e diabetes mellitus; $26(23,6 \%)$ respondem positivamenteà relação de infecções orais e quadros de acidente vascular cerebral, assim como $24(21,8 \%)$ acreditam que patógenos orais podem interferir no nascimento prematuro e baixo peso (PLBW).

No questionário referente à coleta de informações sobre a história odontológica $(\mathrm{HO})$ durante a anamnese, dos 110 entrevistados, apenas três $(2,7 \%)$ afirmaram ter por hábito coletar esses dados, 64 (58,2\%) reconheceram ser esta uma atitude condicional e $43(39,1 \%)$ responderam que, dentro da história patológica pregressa (HPP), os dados sobre a HO não são coletados.

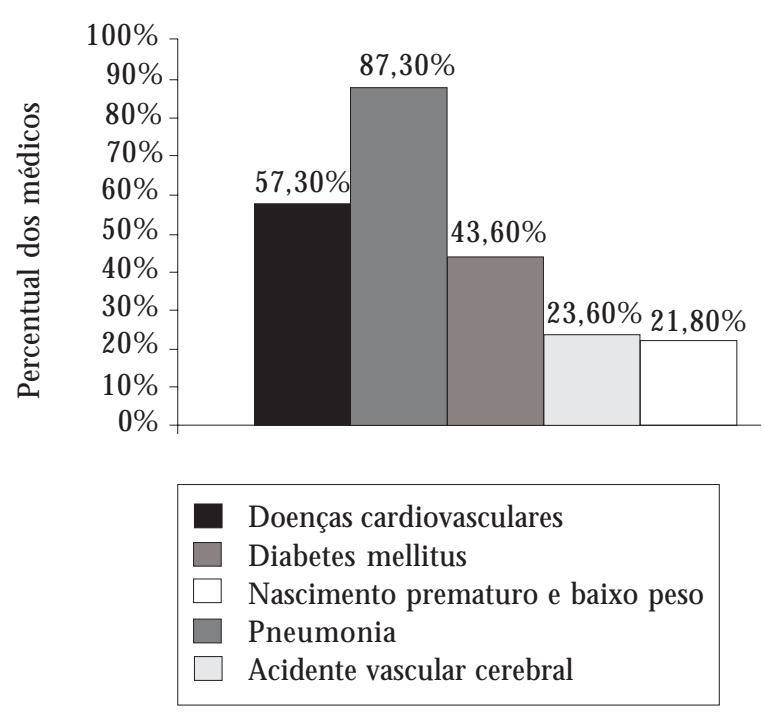

Gráfico 1. Distribuição percentual da concordância dos entrevistados sobre a possível relação das doenças orais e doenças sistêmicas.

Dentreas causas mais relevantes citadas como condição para a coleta de informações sobre a HO, podemos observar: pacientes com doenças orovalvares ou aqueles que serão submetidos à cirurgia para a troca de prótese valvar; casos ou suspeita de endocardite; alterações na cavidade oral, tais como presença de dentes cariados, presença de próteses mal adaptadas e presença de doença periodontal; quando o paciente refere queixa específica à cavidade bucal.

Dos 110 médicos que participaram do estudo, $99(90,0 \%)$ demonstraram ter o hábito de pedir parecer a outros profissionais de saúde no diagnóstico e plano de tratamento das enfermidades que acometem seus pacientes. Foram citadas 24 especialidades médicas e/ou profissionais de saúde. Os cirurgiões gerais e vasculares (50,50\% - 50) apareceram como os profissionais mais solicitados pel os cardiologistas eintensivistas; seguidos pelos neurologistas (35,40\% - 35); odontólogos (27,30\% - 27), infectologistas (24,20\% - 24), nefrologistas (22,20\% - 22), pneumologistas (20,20\% - 20), fisioterapeutas e clíni$\cos (16,20 \%-16)$.

Quando questionados sobre o exame da cavidade oral, dentre todos os 110 , catorze (12,7\%) afirmaram que não possuem o hábito de exame da cavidade bucal, 41 (37,3\%) responderam que rotineiramente examinam a cavidade bucal de 
seus pacientes e $55(50,0 \%)$ declararam ser essa uma atitude condicional a alguma observação durante a anamnese. Não houve diferença estatisticamentesignificativa entre os médicos segundo os hospitais $(p>0,05)$.

O Gráfico 2 apresenta a distribuição percentual das causas ou situações mais expressivas citadas pelos médicos que justificariam o exame da cavidade bucal de seus pacientes. Dentre os 55 $(100,0 \%)$ médicos que afirmaram ser esta uma conduta condicional, dezessete $(29,3 \%)$ relataram que alterações na cavidade oral, tais como má conservação dentária, uso de próteses deficientes, presença de doença periodontal, presença de sangramento, seriam indicativos da necessidade de se realizar o exame da cavidade bucal dos enfermos; doze $(20,70 \%)$ citaram que realizam esse exame na presença de pacientes portadores de doenças or oval vares; onze $(19,00 \%)$, em quadros ou suspeita de endocardite; outros onze $(19,00 \%)$ afirmaram realizar esse procedimento apenas quando o paciente refere queixa à cavidade bucal; oito $(13,80 \%)$ responderam que quando necessitam verificar a hidratação dos pacien- tes, a abordagem da cavidade oral é realizada, e outros oito também $(13,80 \%)$ examinam a cavidade bucal quando o paciente necessita de suporte ventilatório.

Quando questionados se os pacientes submetidos a procedimentos cirúrgicos passam por uma inspeção bucal prévia, dos 110 indivíduos, $23(20,9 \%)$ responderam quenão realizam o exameda cavidadeoral no pré-cirúrgico e 75 (68,2\%) afirmaram que a cavidade oral é inspecionada antes do paciente ser submetido à cirurgia. Não houve diferença estatística significativa entre os hospitais $(p>0,05)$.

O Gráfico 3 ilustra a distribuição percentual dos médicos segundo a finalidade da inspeção intra-oral dentre aquel es que afirmaram realizar o exame clínico da cavidade bucal antes do procedimento cirúrgico. Dentre estes, $75,(60,00 \%)$ procuram por dentes cariados; $78,9 \%$ preocupam-se com a presença de abscessos ou doenças gengivais; $64,40 \%$, com a presença de próteses; 43,30\% buscam se há evidências de ferimentos e $12,20 \%$ afirmam ser esta uma rotina pré-operatória para cirurgias valvares.

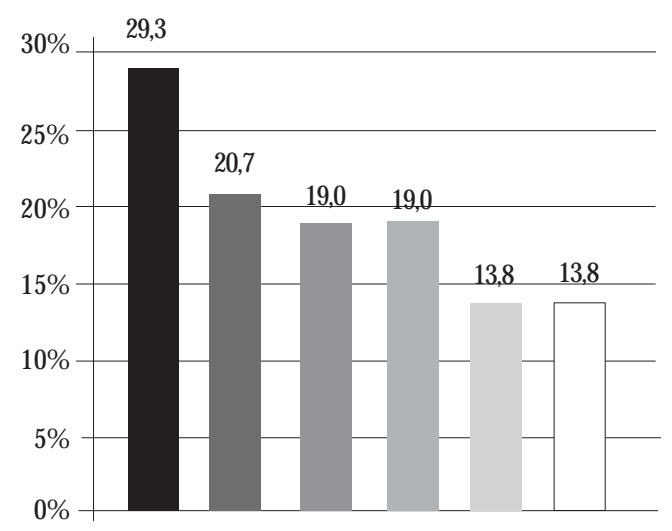

Alteração visual macroscópica na cavidade oral Pacientes portadores de doenças orovalvares Suspeita de endocardite

Quando o paciente refere queixa à cavidade oral Verificar a hidratação do paciente

Necessidade de suporte ventilatório

Gráfico 2. Distribuição percentual das causas ou condições que, segundo os médicos, os levariam a examinar a cavidade oral de seus pacientes.

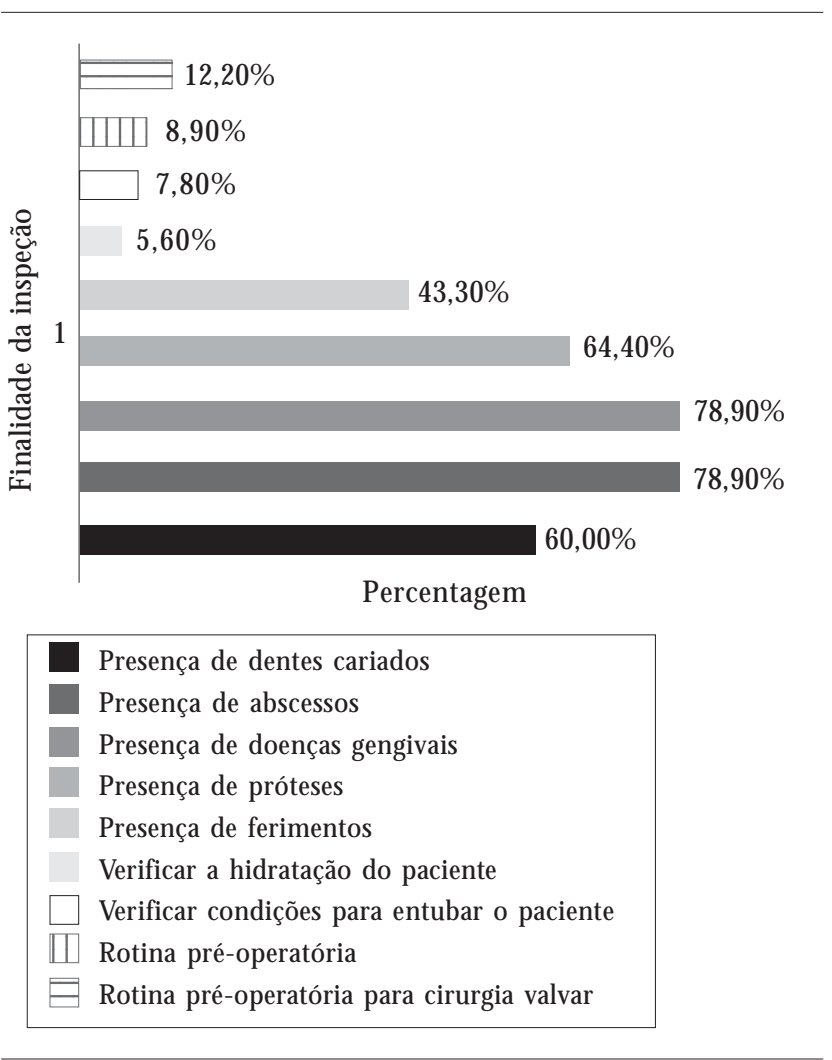

Gráfico 3. Distribuição percentual dos médicos segundo a finalidade do exame clínico oral pré-cirúrgico. 
Dentreaqueles quenegaram realizar o exame bucal prévio a procedimentos cirúrgicos ( 23 indivíduos $=20,90 \%$ ), buscou-se saber quais os motivos que justificariam a não realização desta inspeção. Somente 22 indivíduos responderam a esta questão. Os motivos ou situações citadas que justificariam tal conduta foram a falta de hábito ou esquecimento, a falta de preparo e a setorização da área de atuação dos profissionais de saúde ea dificuldade em realizar o exame oral em seus pacientes pois, frequentemente, estes se encontram portando tubo orotraqueal.

Com relação ao conhecimento médico sobre a existência de um protocolo específico para a manutenção dehigieneecontrole deinfecção oral nos pacientes internados nos CTI e UC apresentou os seguintes resultados, todos os médicos responderam a esta questão; dentre estes, 42 $(38,2 \%)$ afirmam não existir um protocolo específico para tal finalidade, $60(54,5 \%)$ responderam que existe padronização para tal procedimento e oito $(7,3 \%)$ informaram não saber responder a esse questionamento $(p>0,05)$;

Uma questão referia-se aos métodos de controle da flora oral utilizados na unidade hospitalar, onde $79,40 \%$ dos médicos responderam que as soluções de bochecho eram utilizadas para tal finalidade; 53,30\% citaram a limpeza da cavidade com gazee $38,30 \%$ informaram que a escovação era também utilizada para estefim. Não houve diferença estatística significativa entre as unidades hospitalares $(p>0,05)$;

O cloreto de cetilpriridínio (Cepacol ${ }^{\circledR}$ ) foi a substância mais citada pelos médicos dentre os colutórios bucais utilizados como solução nos procedimentos de higieneoral $(76,40 \%)$. A solução de digluconato de clorexidina (Periogard ${ }^{\circledR}$ ) correspondeu a $32,70 \%$ das respostas e o Biote$n^{\circledast}$ (solução contendo lactoferrina, lisozima e lactoperoxidase) foi citado como solução de escolha por $17,30 \%$ dos médicos.

Sobre o conhecimento médico a respeito da posologia prescrita no CTI e UC para as substâncias citadas anteriormente, 38,0\% dos médicos informaram utilizar a solução uma vez ao dia, $18,20 \%$ deles citaram que utilizam a substância de doze em doze horas; $10,0 \%$ três vezes ao dia, $8,2 \%$ quatro vezes ao dia e $23,6 \%$ dos indivíduos relataram não saber a posologia utilizada no CTI ou UC.

Foi perguntado como era realizada a prevenção de infecções secundárias nos pacientes internados e entubados impossibilitados de realizar a prática e os métodos de controle e placa autonomamente. Dentreos 110 médicos, 71 (64,5\%) in- formaram ser através de gaze embebida em solução de bochecho, procedimento realizado pelos enfermeiros; quinze (13,6\%) apenas citaram que utilizam soluções de bochecho para tal finalidade; onze (10\%) afirmaram ser através dehigiene oral diária; nove (8,2\%) disseram ser através da aspiração de secreção da cavidade oral; dezessete (15,5\%) através de conduta asséptica, cabeceira elevada e proteção gástrica; quatro (3,6\%) informaram que os procedimentos são realizados pelo setor de enfermagem, mas que desconhecem exatamente o que é realizado; um (0,9\%) disse que sua unidade hospitalar não dispunha de rotina para esse objetivo; outro indivíduo $(0,9 \%)$ declarou que esses procedimentos não são realizados devido a outras prioridades etrês $(2,7 \%)$ declararam não possuir essa informação.

Quando perguntados sobre como o profissional de saúde poderia ajudar seus pacientes no controle da infecção da cavidadeoral, 62 (56,4\%) indivíduos informaram acreditar que a orientação dos pacientes quanto aos hábitos alimentares e hábitos de higiene oral seria a melhor maneira de al cançar este objetivo; dezesseis (14,5\%) declararam que a orientação dos profissionais de saúde, enfermeiros e equipe médica seria um bom caminho a se seguir; oito (7,3\%) afirmam que através de padronização e treinamento podem conseguir bons resultados; 32 (29,1\%) acham que 0 encaminhamento ao profissional específico seria uma forma de ajudar seus pacientes na controle da infecção da cavidade oral.

\section{Discussão}

A doença periodontal é uma condição infecciosa bacteriana multifatorial, de natureza inflamatória, na qual a placa bacteriana é o fator iniciador da doença e o acúmulo do biofilme destrói os tecidos de sustentação do órgão dental. Muitos são os estudos epidemiológicos que têm sugerido que infecções orais, especialmente as doenças periodontais, possam ser fator de risco para doenças sistêmicas. Embora 83 (75,4\%) dos entrevistados informem já ter ouvido falar sobre 0 termo medicina periodontal, apenas 33 (30,0\%) declararam ter lido algo a respeito. Deum modo geral, 57,30\% responderam positivamente à relação entre as doenças orais e doenças cardiovasculares e 87,30\%, infecções respiratórias. Entretanto, apenas $23,60 \%$ reconhecem que os patógenos periodontais podem influenciar o curso da diabetes mellitus, assim como $78,20 \%$ desconhecem ou não concordam que gestantes com 
doença periodontal possam gerar fetos prematuros e de baixo peso.

A secreção salivar desempenha um dinâmico papel na manutenção da saúde oral e quando suprimida ou diminuída causa sensação de boca seca, dificuldade de deglutição do bolo al imentar e aumento do risco de desenvolvimento de infecções oportunistas. Amerongem et al. ${ }^{12}$ citam que a presença no fluido salivar deimunoglobulinase enzimas antimicrobianas, como a lactoferrina, lisozima elactoperoxidase, dentre outras, édefundamental importância para a defesa do organismo e manutenção da saúde. Em muitos casos, pacientes sedados e internados em centros de terapia intensiva apresentam baixa de secreção salivar e dentro de duas semanas apresentam mudanças na flora oral microbiana, favorecendo a prevalência de bactérias gram-negativas e, consequentemente, possibilitan do quadros deinfecções pulmonares por aspiração desses patógenos.

Dentre aqueles que citaram necessidade de suporte ventilatório como justificativa ao exame clínico da cavidade bucal, declararam fazêlo para verificar as condições anatômicas, dentárias ou protéticas que poderiam inviabilizar a passagem do tubo orotraqueal; entretanto, estudos mostram que a pneumonia é a infecção nosocomial mais comum dentro das unidades de terapia intensiva, contribuindo de forma significativa com as taxas demorbidadeemortalidadenestescentros. Segundo Limeback ${ }^{13}$, a pneumonia nosocomial é responsável por 10 a 15\% detodas as infecções adquiridas em hospitais, principalmente em Unidades deTerapia Intensiva(UTI) e 20 a $50 \%$ dos pacientes quea contraem falecem. Equipamentos deventilação tornam-se contaminados pelas próprias bactérias dos pacientes eparecem ser um fator derisco significante na etiologia dessa doença.

Dentre osindivíduos que afirmaram não realizar o exame pré-operatório da cavidade oral dos pacientes submetidos a intervenções cirúrgicas, alguns (13,60\%) citaram a dificuldade derealizar a inspeção da cavidade oral devido à pre sença do tubo deventilação pulmonar como justificativa para tal negligência.

As doenças orovalvares e quadros de endocardite foram também bastante citados pelos médicos entrevistados como relevante para 0 exame clínico da cavidade bucal. Quando os médicos referem-se a quadros de endocardite e pacientes portadores de doenças orovalvares, estes demonstraram estar a par da literatura sobre as possíveis consequências de uma bacteremia transitória seguinte a procedimentos cirúrgicos e sobre as considerações da Associação
Americana de Cardiologia (AHA) a respeito das condutas preventivas frente aos riscos de endocardite. A endocardite infecciosa é causada pela infecção do tecido endotelial do coração, resultante da colonização microbiana das válvulas cardíacas naturais danificadas ou protéticas. Mask ${ }^{14}$ cita que o paciente odontológico com doença orovalvar apresenta um certo desafio e os riscos incluem instabilidade hemodinâmica, arritmia cardíaca e endocardite infecciosa.

Atualmente, inúmeros produtos para higiene bucal e controle da flora microbiana encontramse disponíveis no mercado e cabe aos profissionais de saúde eàs pessoas responsáveis pela aquisição dos mesmos buscar informações dentro da ampla literatura existente sobre eficácia, posologia e principalmente indicação. Embora muitos trabalhos demonstrem claramente a eficácia do digluconato de clorexidina no controle químico do biofilme dental, somente o hospital particular apresentou um percentual bastante significativo no uso desta solução, embora, na unidade federal, 38,50\% dos seus representantes tenham citado a clorexidina. Nos demais hospitais, os resultados demonstraram valores predominantes para o cloreto de cetilpiridínio. Diante de um quadro geral, a droga mais utilizada não é a de escolha segundo a literatura vigente. 0 cloreto de cetilpiridínio, quando usado oralmente, se liga rapidamente à placa e à superfície dental; entretanto, se desprende facilmente perdendo o seu efeito.

A penas $27,3 \%$ dos médicos possuem o hábito de pedir parecer aos cirurgiões-dentistas e somente $11,80 \%$ dos profissionais afirmaram ter recebido treinamento para avaliar a condição oral de seus pacientes e assim poder interpretar os achados bucais durante a anamnese, denotando claramente a falta de interdisciplinaridade entre as classes médica e odontológica, fato esse fundamental para o crescimento e melhora dos serviços de assistência à saúde.

Deseja-se a otimização dos serviços de saúde, fruto da diminuição do risco eincidência deinfecções hospitalares secundárias e da melhora no prognóstico dos pacientes, da redução da morbidade e mortalidade nos centros de terapia intensiva eunidades coronarianas eda redução do tempo e dos custos de internação, viabilizando, desta forma, leitos, verba e consequentemente assistência à demanda reprimida da população. Essas observações enfatizam a necessidade de início precoce de programas preventivos, programas estes direcionados não somente às massas populacionais, mas principalmenteàs populações derisco e aos diversos profissionais de saúde. 
A hiperespecialização não possibilita a percepção do global, tanto quanto do essencial, fragmentando em partes o que poderia ser contextual. 0 melhor seria uma abordagem holística do ser humano, proporcionada pela troca de informação e pelo entrosamento entre as especialidades. 0 ser humano necessita ser abordado como um todo, em que a sua saúde não possa ser dissociada em áreas.

\section{Colaboradores}

S Kahn e WAS Machado participaram da concepção teórica e delineamento da pesquisa; ES $M$ angialardo executou a coleta, avaliação dos dados e redação; $\mathrm{CH}$ Garcia participou da redação e parte gráfica; J Galan Júnior e FM Namen contribuíram na redação e avaliação dos dados.

\section{Referências}

1. M ealey BL. Influence of periodontal infections on systemic health. Periodontology 2000; 1999; 21:197209.

2. Meyer DH, Fives-Taylor PM. Oral pathogens: From dental plaque to cardiac disease. Curr Opin Microbiolol 1998; 1(1):88-95.

3. Li X, Kolltveit K, Tronstad L, OIsen I. Systemic disease caused by oral infection. Clin Microbiol Rev 2000; 13(4):547-558.

4. Offenbacher S, Katz V, Fertik G, Collins J, Boyd D, M aynor G, M cKaig R, Beck J. Periodontal Infection as a possible risk factor for preterm low birth weight. J Periodontol. 1996; 67(10):1103-1113.

5. Scannapieco FA, Bush RB, Paju S. Associations between periodontal disease and risk for nosocomial bacterial pneumonia and chronic obstructive pulmonary disease. A systematic review. Ann Periodontol 2003; 8:54-69.

6. Quagliarello V, Ginter S, Han L, Van Ness P, Allore $H$, Tinetti $M$. Modifiable risk factors for nursing home-acquired pneumonia. Clin Infect Dis 2005; 40:1-6.

7. Beck J, Slade G, Offenbacher S. Oral disease, cardiovascular disease and systemic inflammation. Periodontol 2000; 23:110-120.

8. Yoneyama $T$, Yoshida $M$, Ohrui $T$, Mukaiyama $H$, Okamoto H, Hoshiba K, I hara S, Yanagisawa S, Ariumi S, Morita T, Mizuno Y, Ohsawa T, Akagawa $Y$, Hashimoto K, Sasaki H, Oral Care Working Group.

9. Oral care reduces pneumonia in older patients in nursing homes. J Am Geriatr Soc 2002; 50:430-433. Adachi M, Ishihara K, Okuda K. Effect of professional oral health care on the elderly living in nursing homes. Oral surgery oral medicine oral pathology 2002; 94(2):191-195. 
10. Fourrier F, Cau-Pottier E, Boutigny H, Roussel-Delvallez $M$, Jourdain $M$, Chopin $C$. Effects of dental plaque antiseptic decontamination on bacterial colonization and nosocomial infections in critically ill patients. Intensive Care M ed 2000; 26:1239-1247.

11. De Riso AJ, Dillon TA, Peterson AC. Chlorhexidine gluconate $0,12 \%$ oral rinse reduces the incidence of total nosocomial respiratory infection and nonprophylactic systemic antibiotic use in patients undergoing heart surgery. Chest 1996; 109(6):1556-1561.

12. Amerongen $A V N$, Veerman $E C I$. Saliva- the defender of the oral cavity. Oral Diseases 2002; 8:12-22.

13. Limeback $\mathrm{H}$. Implications of oral infections on systemic diseases in the institutionalized elderly with a special focus on pneumonia. Ann Periodontol 1998; 3(1):262-275.

14. Mask AG. Medical control cardiovascular disease. Periodontol 2000; 23:136-141.

Artigo apresentado em 20/10/2007

Aprovado em 07/05/2008 